\title{
Soil transmitted helminths and schistosoma mansoni infections among school children in zarima town, northwest Ethiopia
}

\author{
Abebe Alemu*, Asmamaw Atnafu, Zelalem Addis, Yitayal Shiferaw, Takele Teklu, Biniam Mathewos, Wubet Birhan, \\ Simon Gebretsadik and Baye Gelaw
}

\begin{abstract}
Background: In Ethiopia, because of low quality drinking water supply and latrine coverage, helminths infections are the second most predominant causes of outpatient morbidity. Indeed, there is a scarcity of information on the prevalence of soil transmitted helminths and Schistosomiasis in Ethiopia, special in study area. Therefore, the aim of this study was to determine the prevalence and associated risk factors of soil transmitted helminths and intestinal Schistosomiasis.

Methods: Cross-sectional study was conducted among 319 school children of Zarima town from April 1 to May 25,2009 . A pre-tested structured questionnaire was used to collect socio-demographic data and possible risk factors exposure. Early morning stool samples were collected and a Kato Katz semi concentration technique was used to examine and count parasitic load by compound light microscope. Data entry and analysis was done using SPSS-15 version and $p$-value $<0.05$ considered statistically significant.
\end{abstract}

Results: Out of 319 study subjects, 263 (82.4\%) of the study participants infected with one or more parasites. From soil transmitted helminths, Ascaris lumbricoides was the predominant isolate (22\%) followed by Hookworms (19\%) and Trichuris trichiura (2.5\%). Schistosoma mansoni was also isolated in $37.9 \%$ of the study participants. Hookworm and S. mansoni infections showed statistically significant associations with shoe wearing and swimming habit of school children, respectively.

Conclusion: Prevalence of soil transmitted helminths (STH) and S.mansoni was high and the diseases were still major health problem in the study area which alerts public health intervention as soon as possible.

\section{Background}

Soil transmitted helminthic infections and Schistosomiasis are among the widely spread chronic infections in the world. Globally 2 billion individuals are infected with helminths, out of these majorities live in resource-poor settings $[1,2]$. World health organization (WHO) estimated the common STHIs in world as: 250 million cases for Ascariasis, 151 million cases of hookworm diseases, 100 million cases of Strongyloidiasis and 45.5 million cases of Trichuriasis [3]. Schistosomiasis is also remains one of the most prevalent parasitic diseases in the world. It is endemic in 76 countries and continues to be public

\footnotetext{
* Correspondence: yanbule@gmail.com

Department of Medical Laboratory Sciences, College of Medicine and Health Sciences, University of Gondar, Gondar, Ethiopia
}

health concern in developing countries. Approximately $80 \%$ of the 200 million people infected world-wide live in sub-Saharan Africa where Schistosoma mansoni and Schistosoma haematobium are widespread $[4,5]$.

The occurrence of helminthic infections is associated with socioeconomic, environmental and other factors like, ignorance of simple health promoting factors and overcrowding, limited access to clean water, tropical climate and low altitude [2]. School age children are one of the groups at high-risk for intestinal parasitic infections. Factors like poor developments of hygienic habits, immune system and over-crowding contributes for infection [6]. The adverse effects of intestinal parasites among children are diverse and alarming. Intestinal parasitic infections have detrimental effects on the survival, 
appetite, growth and physical fatnesses, school attendance and cognitive performance of school age children [7-11].

Ethiopia has one of the lowest quality drinking water supply and latrine coverage in the world [12]. Because of this and other reasons intestinal parasites have been widespread in Ethiopia and parasitic helminthic infections are the second most predominant causes of outpatient morbidity in the country. Many reports illustrated that Ascariasis is the most prevalent intestinal parasitic infection in different communities usually occurring together with trichuriasis. Hookworm infection, Strongyloidiasis and Enterobiasis are also public health problem though the magnitude is lesser compared to Ascariasis [13]. Also schistosomiasis is common in northern region as compared to south and south west regions of Ethiopia [14].

Intervention against $\mathrm{STH}$ and Schistosoma infections are based on regular anti-helminthic treatment, improved water supply, sanitation and health education [15-17]. STH infections have not been targeted for control in Ethiopia [18], though mass de-worming as a component of the Enhanced Outreach Strategy (EOS) targeting under five children started in 2004 [19]. Low-cost, high-coverage delivery of anti-helminthic treatment has been achieved in some settings [20] but improving sanitation is more complex. In Ethiopia, for example, levels of access to improved sanitation in rural areas are very low (5.4\%) making evaluation of other components of intervention important [21].

Prevalence of intestinal helminths and other intestinal parasites have been studied in different of tropics and subtropics including Ethiopia [22-32]. Although many studies previously conducted in Ethiopia, gave due attention to distribution of different intestinal parasites on different altitudes in different community groups such as preschool children, school children and other groups confined to camps and refugees, the prevalence of STH and schistosomiasis was not well addressed indifferent parts of Ethiopia including our study area. Therefore, the aim of this study was to determine the prevalence and associated risk factors of soil transmitted helminths and Schistosoma mansoni infection among school children in Zarima town, North Gondar, North West Ethiopia. As result this study envisages that it might strengthen the information so far for scaling up and to design effective communication strategy to combat STH and S. mansoni in the study area.

\section{Methods}

\section{Study area}

Cross-sectional study was conducted from April 1 to May 25, 2009 among elementary school children of Zarima town which is one of small town in "Adarkay" woreda in North Gondar. It is $140 \mathrm{~km}$ far from Gondar town. The town has approximately a total population of about
20,000 [33]. The area is predominately rural and most residents live in villages as agriculturists which is mixed agriculture; growing maize, teff (Eragrostos teff) and wheat. The altitude of the town range from 1000-2400 meter above see level and the topography shows hills and plain land with springs, streams and rivers which are often source of water for domestic and other uses for the communities in the town and around the town. These predispose the children to water borne diseases during swimming, washing, playing, and crossing the water. The town has only one government owned general elementary school which encompasses 25 teaching sections within a single compound.

\section{Sample size determination and sampling techniques}

The sample size for this study was calculated by using single proportion formula at $95 \%$ confidence interval (CI) level $(Z(1-\alpha ́ \alpha)=1.96)$, an expected prevalence of $50 \%$ since there was no study conducted regarding this topic in the area and 5\% marginal error. Then the sample size was calculated as $\mathrm{n}=[\mathrm{Z} 1-\alpha / 2] 2 P(1-p] / d^{2}$, Where: $\mathrm{n}=$ sample size, $\mathrm{P}=$ proportion problem in the study area, $\mathrm{Z}$ $1-\alpha / 2=$ CI of $95 \%, d=$ Marginal error to be tolerated. By adding $10 \%$ of contingency 319 students were included in our study.

The sample size which is determined earlier was used to calculate the proportion of students to be selected from each section. Using registration list, simple random sampling method was employed to select students from each section using a table of random numbers and when the selected student was absent student before or after the indicated one was sampled for replacement.

\section{Socio demography and risk factor assessment}

Well structured questionnaire based on the known risk factors for STHs and Schistosoma was locally developed specifically in English version by the research team. It was later translated into the Amharic, local language of the study area. Comparisons were made on the consistency of the two versions. The questionnaires address students' socio-demographic information, hand washing, shoe wearing and swimming habit, presence of latrine and its usage, water source for domestic use and other risk factors around. A pretest was conducted among five percent of the total sample size that was selected randomly from 25 sections on which cross sectional study was conducted by trained data collectors and any ambiguous questions and repetitive ideas were corrected. Additional response categories were also added based on the pretest findings. When the children were identified, the purpose, objectives and benefits of the study were explained to the parents and consent for participation sought. Those who consented were interviewed at the school. All households were inspected to assess the type and condition of latrine, 
status of the compound, absence or presence of refuse dumps, soiling of the compound and whether the home reared cattle. The type of water sources from which respondents collected water and their accessibility was also noted.

\section{Stool sample collection, processing and light microscope detection}

After interviewed the students were then given labeled stool containers with tight covers bearing serial numbers of the subjects and were asked to put about $5 \mathrm{~g}$ of stool the following morning. All the stool samples were received the following day at an organized central place and processed using direct saline wet mount for motile intestinal parasites. Stool samples also processed using Kato-Katz smear technique [34]. The slides were examined under light microscope at X100 and X400 magnifications. The parts of the slides was re-examined for assurance of quality control. A small portion of the stool samples were also preserved in $10 \%$ formalin for repeating the tests whenever required.

\section{Quality control}

For quality purpose Proper thin wet mount and KatoKatz techniques was prepared using standard amount of specimen and examined within a given time. Ten percent of the slides was randomly selected and re-examined at the end by experienced laboratory technologist who was blind for the first examination result. The result of laboratory examination was recorded on well prepared format carefully and finally it was attached with the questionnaire.

\section{Data management and analysis}

After data collection process, the data were checked for completeness. Then the result of laboratory examination was recorded on well prepared format carefully and finally was attached with the questionnaire. The study population was further divided into three age groups, i.e. 5-9, 10-14 and 15-19 years. The egg per gram stool (EPG) was used to categorize intensity of infection. The intensity of infection was classified as low (when EPG was $<200$ ), moderate (EPG $=201-800$ ), and heavy (EPG $>800$ ). The frequency distribution of both dependent and independent variables were worked. The dependent variables were any STH and Schistosoma infections in the children. Potential risk factors explored include sociodemographic characteristics, hand washing, shoe wearing and swimming habits, presence of latrine and its usage and others. The data was entered into a computer using SPSS (15 version) statistical packages and univariate association between each exposure and the presence of infection was assessed using the Chi-squared test and odds ratios with $95 \%$ CI were computed as measures of association. P-value less than 0.05 were taken as statistical significant association between dependent and independent variables.

\section{Ethical consideration}

Ethical clearance was obtained from University of Gondar, College of medicine and health sciences and department of medical laboratory sciences. Additionally, after explaining the importance of the study briefly an informed written consent was obtained from Parents of the study subjects. Anyone not willing to take part in the study had full right to do so and confidentiality of the study participants was also maintained. Those students who were positive for intestinal parasites were treated accordingly by appropriate antiparasitic drugs.

\section{Results}

Socio-demographic characteristics of study subjects

A total of 319 school children (157 males and 162 females) were included in the study. The age range of interviewed children was 5 to 17 years with median of 11 $( \pm 1.2 \mathrm{sd})$ years. The majority $89.4 \%$ and $85.9 \%$ of students were Amahara by ethnicity and Orthodox Christians by religion, respectively. $70.8 \%$ of student's family heads were illiterate and agriculture was their major occupation (76.4\%).

\section{Prevalence and intensity of soil transmitted helminths and Schistosoma mansoni}

Out of 319 study subjects 263 (82.4\%) and 251(78.1\%) had one or more parasites in Kato Katz and wet mount techniques, respectively. From soil transmitted helminths, A. lumbricoides was the predominant isolate (22\%) followed byhookworms (19\%) and T. trichiura (2.5\%). S. mansoni was also isolated in $37.9 \%$ of the study participants. Though statistically significant difference was not observed in parasitic infection among males and females but infections due to A. lumbricoides and Hookworms appeared relatively higher in males than in females. On the other hand more females than males were affected by T. trichiura and S.mansoni (Table 1).

More than half (53.9\%) of children had a single infection, while $23.2 \%$ of children had double infections and 5.3\% had triple infections. From the infected children, $45.5 \%$, $43.7 \%$ and $10.8 \%$ harbored single, double and triple parasites, respectively. Higher rate (10.1\%) of S. mansoni coinfection with $A$. lumbricoides was observed followed by hookworms (7.2\%) and T. trichiura (0.9\%). There was no statistically significant association between multiple infection and sex and age. The rate of heavy infection was highest for A. lumbricoides (14.1\%) followed by S. mansoni (7.4\%) and Hookworms (3.4\%). In contrast no heavy infection was detected due to T. trichiura (Table 2). On the other hand $38.5 \%, 53.6 \%$ and $7.9 \%$ of the infected children 
Table 1 Prevalence of STH and S. manson $i$ in Children Attending Zarima elementary School, 2009

\begin{tabular}{|c|c|c|c|c|c|c|c|c|}
\hline \multirow[t]{2}{*}{ Parasite $s$ indentified } & \multicolumn{2}{|c|}{ Male $(\mathrm{N}=157)$} & \multicolumn{2}{|c|}{ Female $(\mathrm{N}=162)$} & \multicolumn{2}{|c|}{ Total $(\mathrm{N}=319)$} & \multirow[t]{2}{*}{$\mathrm{X}^{2}$} & \multirow[t]{2}{*}{ P.value } \\
\hline & No & $\%$ & № & $\%$ & No & $\%$ & & \\
\hline S. mansoni & 53 & 33.7 & 68 & 42.2 & 121 & 37.9 & 2.28 & 0.06 \\
\hline A.Lumbricoides & 49 & 31.2 & 21 & 12.9 & 70 & 21.9 & 15.5 & 0.000008 \\
\hline Hookworms & 30 & 19.1 & 30 & 18.5 & 60 & 18.8 & 0.018 & 0.8928 \\
\hline T.trichura & 2 & 1.2 & 6 & 3.7 & 8 & 2.5 & 1.925 & 0.1654 \\
\hline Others & 3 & 1.9 & 1 & 0.6 & 4 & 1.2 & 1.077 & 0.0301 \\
\hline Total & 137 & 87.2 & 126 & 77.7 & 263 & 82.4 & & \\
\hline
\end{tabular}

harboured low, moderate and heavy infection, respectively for different STH and S. mansoni.

\section{Univariate risk factor analysis for soil transmitted helminths and S. mansoni infections}

The distributions of the demographic and risk factors of the subjects are shown in Table 3 . In univariate analyses, no statistical significant association were observed in parasite prevalence between male versus female, first versus second cycle and maternal educational status of the students. Even though there was no overall statistical significant association between age and parasite prevalence; age group between 5-9 years showed statistical significant association compared to other categories $(\mathrm{OR}=3.08 ; 95 \%$ CI 1.017, 9.373, $\mathrm{p}=0.047)$. Similarly significant association in parasite prevalence was observed between family water source (overall p < 0.005 ) with the highest prevalence was observed in those getting their water from protected spring (89.5\%), and the lowest in those using pipe line (74.4\%). In addition, frequency of hand washing habit with soap was significantly associated with children infection with increased risk seen for infrequent hand washing habit with soap compared to daily use (overall $\mathrm{p}=0.000$, OR 0.292, 95\% CI 0.130-0.652) (Table 3).

Separate univariate analysis for specific parasite prevalence and risk factors indicated significant positive associations were seen between presence of Hook worm infection and none-shoe wearing habits $(\mathrm{OR}=2.1 ; 95 \%$ CI $1.55-4.494, \mathrm{p}<0.001)$ and $S$. mansoni infection and those children who had swimming habit in the river
$(\mathrm{OR}=3.2 ; 95 \%$ CI $2.53-8.38, \mathrm{p}<0.001)($ data not presented here).

\section{Discussion}

Soil-transmitted helminths and schistosomiasis infections are among the most prevalent afflictions of humans who live in areas of poverty in the developing world. Because of the geographic overlap of these afflictions and their impact on children and adolescents, World Health Organization (WHO); the World Bank; and other United Nations agencies and bilateral, and civil society are working to integrate STH and Schistosoma control through a program of periodic schoolbased targeted Antihelminthic drug treatments [16,17].

Despite presence of the deworming program for control of STH and S. mansoni currently in study area, the finding this study showed that over all prevalence STH and S. mansoni was high $(82.4 \%)$ and the diseases were still a major health problem of the study area. S. mansoni was most prevalent (37.9\%,) followed $A$. lumbricoides, the Hookworms, T. trichiura and any other helminths, $22 \%$, $19 \%, 2.5 \%$ and $1.5 \%$, respectively. The finding of this study is quite high when compared to other studies conducted in Gondar regions and other parts of Ethiopia [23-26].

A cross sectional survey conducted on STH and $S$. mansoni infection among school children in Chilga district, North West Ethiopia [22] reported that the over all prevalence rate for one or multiple parasitic infections in children was $68.4 \%$ and infection due to $A$. lumbricoides was the most prevalent (42.9\%, range: $22.9 \%-68.6 \%)$

Table 2 Categorization of Intensity of Infection Due to S. mansoni, A. Lumbricoides, T. trichiura and the Hookworms in School Children in Zarima Town, 2009

\begin{tabular}{|c|c|c|c|c|c|c|c|c|}
\hline \multirow[t]{2}{*}{ Infection status } & \multicolumn{2}{|c|}{ S.mansoni } & \multicolumn{2}{|c|}{ A.Lumbricoides } & \multicolumn{2}{|c|}{ Hookworms } & \multicolumn{2}{|c|}{ T. trichiura } \\
\hline & No & $\%$ & No & $\%$ & No & $\%$ & No & $\%$ \\
\hline Negative & 198 & 62.1 & 193 & 60.5 & 203 & 63.6 & 311 & 97.5 \\
\hline Low & 32 & 10 & 20 & 6.3 & 39 & 12.2 & 6 & 1.9 \\
\hline Moderate & 80 & 25 & 40 & 12.5 & 19 & 6 & 2 & 0.6 \\
\hline Heavy & 9 & 2.9 & 10 & 3.1 & 2 & 0.6 & 0 & 0 \\
\hline Total positive & 1218 & 37.9 & 70 & 21.9 & 60 & 18.8 & 8 & 2.5 \\
\hline Total & 319 & 100 & 319 & 100 & 319 & 100 & 319 & 100 \\
\hline
\end{tabular}


Table 3 Univariate risk factor analysis for soil transmitted helminths and S. mansoni infections among school children in Zarima town, northwest Ethiopia, 2009

\begin{tabular}{|c|c|c|c|c|}
\hline \multirow[b]{2}{*}{ Variables } & \multirow[b]{2}{*}{$N(\%)$} & \multicolumn{3}{|c|}{ STH and S.mansoni in the children $(\mathrm{N}=319)$} \\
\hline & & $n(\%)$ & OR $(95 \% \mathrm{Cl})$ & p-value \\
\hline \multicolumn{5}{|l|}{ Demographics variables } \\
\hline \multicolumn{5}{|l|}{ sex } \\
\hline Male & 157(49.2) & 137(87.3) & $0.913(0.827,1007)$ & 0.067 \\
\hline Female & $162(50.8)$ & $126(77.7)$ & & \\
\hline \multicolumn{5}{|l|}{ Age categories } \\
\hline $5-9$ & $47(14.7)$ & $43(91.5)$ & $3.08(1.017,9.373)$ & 0.047 \\
\hline $10-14$ & $151(47.3)$ & $129(85.4)$ & $1.68(0.904,3.134)$ & 0.101 \\
\hline 15-19 & $121(38)$ & $91(75.2)$ & 1 & 0.071 \\
\hline \multicolumn{5}{|l|}{ Education level } \\
\hline First cycle(1-4) & $160(50.2)$ & 139(86.9) & $0.650(0.329,1.093)$ & 0.093 \\
\hline Second cycle(5-8) & 159(49.8) & 124(77.9) & & \\
\hline \multicolumn{5}{|l|}{ Mother's education } \\
\hline Illiterate & 226(70.8) & $191(84.5)$ & $0.764(0.407,1.431)$ & 0.399 \\
\hline Literate & $93(29.2)$ & $72(77.4)$ & & \\
\hline \multicolumn{5}{|l|}{ Risk factors } \\
\hline \multicolumn{5}{|l|}{ Water source } \\
\hline Pipe line & $117(36.7)$ & $87(74.4)$ & 1 & 0.005 \\
\hline Protected spring & $153(48)$ & 134(87.6) & $0.483(0.196,1.190)$ & 0.114 \\
\hline Well & $49(15.3)$ & $42(85.7)$ & $1.427(0.556,3.701)$ & 0.465 \\
\hline \multicolumn{5}{|l|}{ Hand washing with soap } \\
\hline Daily & $30(9.4)$ & 10(33.3) & 1 & $<0.001$ \\
\hline At least once a week & $135(42.3)$ & $112(83)$ & $0.311(0.011,0.086)$ & $<0.001$ \\
\hline Less frequent than once a week & 154(48.3) & $141(91.5)$ & $0.292(0.130,0.652)$ & 0.003 \\
\hline \multicolumn{5}{|l|}{ Latrine type } \\
\hline Private toilet & 132(41.4) & $112(84.8)$ & 1 & 0.829 \\
\hline Public toilet & $30(9.4)$ & $25(83.3)$ & $0.878(0.325,2.616)$ & 0.878 \\
\hline Open field & $157(49.2)$ & $126(80.2)$ & $1.12(0.384,3.27)$ & 0.836 \\
\hline
\end{tabular}

Note: STH = soil transmitted helminths, $\mathrm{N}=$ total number of study participants, $\mathrm{n}=$ number of outcome for each exposure.

followed by the hookworms $(37.7 \%$, range: $28.0 \%-65.5$ $\%)$ S. mansoni (19.4\%, range: $7.0 \%-64.3 \%)$ and T. trichiura infection (14.8\%, range: $12.7 \%-20.8 \%)$. The differences in prevalence among the different communities appear to be associated with environmental sanitation, water supply and socioeconomic status of households, although this needs to be verified in more extensive follow up studies. Other factors related to macro-and microenvironment, time of study, method of examination, etc, do also contribute to the differences in the prevalence and distribution of these intestinal helminths. No significant difference was obtained in infection rates and egg counts among the age and sex of schoolchildren under consideration. This denotes a similar exposure risk to infection by these helminths.

Other study conducted on intestinal helminthic infections in school children in Adarkay District, northwest Ethiopia, [23] reported overall prevalence rates of 55.3\% for S. mansoni, $43.0 \%$ for A lumbricoides, $20.2 \%$ for hookworm and $11.8 \%$ for $T$. trichiura infections. In similar other studies undertaken in school children the same author has recorded infection rates of $41.3 \%$ with $35.0 \%, 16.5 \%$ and $22.8 \%$ for A. lumbricoides, S. mansoni, T. trichiura and hookworm infections, respectively, in the Dembia Plains [24]; and 35.6\%, 17.3\%, 8.5\% 3.3\% for A. lumbricoides, S. mansoni, T. trichiura and hookworm, respectively, in Gondar town and surrounding areas [25-28].

When compared with the above studies which were conducted before in the study area and around the study area prevalence of these parasites are still high and being increasing in the study area. This might be due to climatic condition of the Zarima town because climate is an important determinant of transmission of these infections with adequate moisture and warm temperature essential for larval development in the soil $[29,30]$. Equally important determinants are poverty, inadequate water supplies and sanitation [31]. Therefore, increased prevalence of S.mansoni infection in study area in addition to STH was mainly due to frequent contact of school 
children for washing, swimming and bathing activities with Zarima River which passes the town.

In this study STH and S.mansoni were co-endemic in the study area. The rate of heavy infection was highest for A. lumbricoides (14.1\%) and $14.7 \%$ of the infected children harbored heavy infection for different STH and S. mansoni. There is evidence that individuals with many helminthic infections have been heavier infections with STH and S.mansoni because morbidity from these infections and rate of transmission are directly related to the numbers of worms harbored in the host [32], and the intensity is mainly epidemiological index used to describe soil transmitted helminthic infection. Also the most striking epidemiological features of human helminthic infections are aggregated distributions in human communities, predisposition of individuals to heavy (or light) infection, rapid re-infection following chemotherapy, and age intensity profiles that are typically convex (with the exception of hookworm).

The high prevalence rate of STH and S. mansoni infections encountered among schoolchildren of the study area raises a serious concern. It signifies the fact that children are the highest risk groups in the community and serve as sources of infection and transmission. These parasites are well known to be associated with lowered work capacity and productivity both in children and adults and increased susceptibility to other infections. Helminths also impair the mental and physical development of children $[7,8]$. Again the majority of wormy children are not only infected with one species of worm but they also tend to harbor the heaviest burdens and more than two-thirds of children were infected with one or more helminths.

Both host-specific and environmental factors have been identified that may affect the risk of acquiring or harboring heavy intensity helminthic infections. Some of factors are behavior; household clustering, occupation, poverty, sanitation and urbanization have been associated with these helminthic infections $[1,2]$. The result of this study revealed that age group between 5-9 showed statistical significant association compared to other categories and significant association in parasite prevalence was observed between family water sources. In addition, frequency of hand washing habit with soap was significantly associated with children infection with increased risk seen for infrequent hand washing habit with soap. This finding is almost comparable with other study findings $[22,23,26]$. The high infection rate among 5-9 age groups is may be due to at this age stage the students have less knowledge about sanitation and more active for swimming and playing on soil. So these factors in addition to other unknown factors might be contributed the high prevalence of STH and S. mansoni among 5-9 years age groups.

The strengthen of this study is that it used standard Kato Katz techniques to detect and count parasites ova, qualified laboratory technologists examined the slide in order to not miss the parasite and the questionnaire assessed many risk factors but the study only used single stool sample which may not address day-to-day and intra-stool variations of egg output that can be the limitation of the study.

\section{Concussions}

Prevalence of STH and S.mansoni was quite high and the diseases were still major health problem in the study area. Because of rapid reinfection following chemotherapy, the highly effective drugs now available and the control methods used in study area have not reduced the prevalence of both schistosomiasis and soil transmitted helminths. Therefore, in future other control activities should be focused in addition to deworming program because without improved water supplies and sanitation chemotherapy approach cannot rely on for sustainable reduction in helminthic infection frequency and intensity of infection. There is also a need for community mobilization towards provision of safe and adequate water supply, latrine construction to reduce open field defecation, and health education aimed at bringing behavioral change in the district. Periodic deworming, particularly of the school-aged children with long term improvements of sanitation should be exercised.

\section{Acknowledgements}

The authors appreciate the study participants for their cooperation in providing the necessary information and stool sample. We would also like to extend our heartiest appreciation to Zarima town education office and teachers of Zarima elementary school for the cooperation during data collection.

\section{Authors' contributions}

AA conceived the study, undertook statistical analysis and drafted the manuscript. AA, ZA, YS, TT, BM, WB, SG AND BG initiated the study and made major contributions to the study design and statistical analysis. All authors contributed to the writing of the manuscript and approved the submitted version of the manuscript.

\section{Competing interests}

All authors declare that they have no competing financial or any other interest in relation to their work.

Received: 2 March 2011 Accepted: 9 July 2011 Published: 9 July 2011

\section{References}

1. Charles MN, Lawrence J: Parasitic Infections of the Gastrointestinal Tract: Article Review. Current Gastroenterology Reports 1999, 1282-1291.

2. World health organization: The prevention and control of schistosomiasis and soil transmitted Helminthiasis. Geneva: WHO; 2002.

3. World Health Organization: Control of tropical diseases. Geneva: WHO; 1998.

4. Davis A, Cook C, Zumla A: Schistosomiasis: Manson's Tropical Diseases. London: Elsevier Science;, 21 2003, 1431-1469.

5. WHO Expert Committee: Prevention and Control of Schistosomiasis and Soil-Transmitted Helminthiasis. Technical Report Series Geneva: WHO; 2002.

6. Jarabo M, Garcia-Moran NP, Garcia-Moran Jl: Prevalence of intestinal parasites in a student population. Enferm Infecc Microbiol Clin 1995, 13:464-468. 
7. De Silva NR, Guyatt HL, Bundy DA: Morbidity and mortality due to Ascaris-induced intestinal obstruction. Trans R Soc Trop Med Hyg 1997, 91:31-36.

8. Stephenson LS, Latham MC, Adams EJ, Kinoti SN, Pertet A: Physical fitness, growthland appetite of Kenyan school boys with hookworm, Trichuris trichiura and Ascaris lumbricoides infections are improved four months after a single dose of albendazole. J Nutr 1993, 123:1036-1046.

9. Nokes C, Bundy DA: Compliance and absenteeism in schoolchildren: Implications for helminth control. Trans R Soc Trop Med Hyg 1993, 87:148-152.

10. Hadidjaja P, Bonang E, Suyardi MA, Abidin SA, Ismid IS, Margono SS: The effect of intervention methods on nutritional status and cognitive function of primary school children infected with Ascaris lumbricoides. Am J Trop Med Hyg 1998, 59:791-795.

11. WHO: Diarrhoea, Reducing Mortality From Major Killers Of Children. World Health Report Revised September 1998, Fact Sheet No: 178

12. Kumie A, Ali A: An overview of environmental health status in Ethiopia with particular emphasis to its organization, drinking water and sanitation: a literature survey. Ethiop J Health Dev 2005, 19(2):89-103.

13. Wodemichael T, Endeshaw T, Shibre T, Gebre T, Haddis M, Tilahun D: Intestinal parasitic infections in western Abaya with special reference to Schistosoma mansoni. Ethiop J Health Dev 1999, 13:25-26.

14. Haile G, Jirra C, Mola T: Intestinal parasitism among Jiren elementary and junior secondary school students, southwest Ethiopia. Ethiop J Health Dev 1994, 8:37-41.

15. Albonico M, Montresor A, Crompton DW, Savioli L: Intervention for the control of soil-transmitted helminthiasis in the community. Adv Parasitol 2006, 61:311-48.

16. Crompton DW: How Much Helminthiasis Is There in the World? J Parasitol 1999, 85:397-403.

17. World Bank: School Deworming at a Glance. Public Health at a Glance Series 2003 [http://www.worldbank.org/hnp].

18. Tadesse Z, Hailemariam A, Kolaczinski JH: Potential for integrated control of neglected tropical diseases in Ethiopia. Trans R Soc Trop Med Hyg 2008, 102:213-214.

19. Federal Ministry of Health: Guidelines for the Enhanced Outreach Strategy (EOS) for Child Survival Interventions. Addis Ababa, Ethiopia; 2004.

20. Montresor A, Cong DT, Le Anh T, Ehrhardt A, Montadori E, Thi TD, Le Kanhh T, Albonico A, Palmer KL: Cost containment in a school deworming program targeting over 2.7 million children in Vietnam. Trans R Soc Trop Med Hyg 2007, 101:461-9.

21. Central Statistical Agency and ORC Macro: Ethiopian Demographic and Health Survey. Addis Ababa Ethiopia and Calverton, Maryland: USA; 2006.

22. Leykun J: Soil Transmitted Helminthic Infection and S. mansoni in School Children from Chilga District, North West Ethiopia. Ethiop J Health Science 2001, 11:79-87.

23. Leykun J: Intestinal Helminthic Infection with Special Reference to $S$. mansoni in School Children in Adarkay District, North West Ethiopia. Ethiop J Health Dev 1997, 11:289-94.

24. Leykun J: Schistosomiasis mansoni and geo-Helminthiasis in school children in the Dembia Plains, Northwest Ethiopia. Ethiop J Health Dev 1998, 12:237-244.

25. Leykun J: Intestinal helminth infections in rural and urban school children in Gondar town and the surrounding areas Northwest Ethiopia. SINET: Ethiop J Sci 1999, 22:209-220.

26. Aklilu $L$, Demisse M, Bahta M: Parasitiological survey of Addis Ababa and Debre Zeit school children with special emphasis on Bilharziasis. Ethiop Med J 1986, 6:1-7.

27. Mohammed A: Prevalence of Intestinal Parasites Kito Elementary School Children in Jimma Town, South West Ethiopia. Health student Research at Jimma University; 2003

28. Tsegaye S: Determining the prevalence of Intestinal parasites and Associated Risk Factors in Yebu Elementary School Students, Jimma Zone, South West Ethiopia. Student Research Programmed Community Based Education Jimma University; 2005.

29. Brooker S, Clements A, Bundy D: Global epidemiology, ecology and control of Soil transmitted helminths infections. Adv parasitol 2006, 62:223-65.

30. Brooker $\mathrm{S}$, Micheal E: The potential of geographical information system and remote sensing in the epidemiology and control of human helmeths infection. Adv parasitol 2000, 47:245-88.
31. De silva NR, Brooker S, Hotez PJ, Montresor A, Engels D, Savioli L: Soil transmitted helminths infections: updating the global picture. Trends Parasitol 2003, 19:547-5.

32. Van der Werf MJ, de Vlas SJ, Brooker S, Looman CW, Nagelkerke NJ, Habbema JD, Engels D: Quantification of Clinical Morbidity Associated with Schistosome Infection in sub-Saharan Africa. Acta Tropica 2003, 86:125-39.

33. Federal Democratic Republic of Ethiopia Population Census Commission: Summary and statistical Report of the 2007 Population and Housing Census: Population size by age and sex. Addis Ababa; 2008.

34. Katz N, Chaves A, Pellegrino J: A simple device for quantitative stool thick-smear technique in Schistosoma mansoni. Revista do Instituto de Medicina Tropical de São Paulo 1972, 14:397-400.

Pre-publication history

The pre-publication history for this paper can be accessed here: http://www.biomedcentral.com/1471-2334/11/189/prepub

doi:10.1186/1471-2334-11-189

Cite this article as: Alemu et al:: Soil transmitted helminths and schistosoma mansoni infections among school children in zarima town, northwest Ethiopia. BMC Infectious Diseases 2011 11:189.

\section{Submit your next manuscript to BioMed Central and take full advantage of:}

- Convenient online submission

- Thorough peer review

- No space constraints or color figure charges

- Immediate publication on acceptance

- Inclusion in PubMed, CAS, Scopus and Google Scholar

- Research which is freely available for redistribution

Submit your manuscript at www.biomedcentral.com/submit
C) Biomed Central 